\title{
Potassium responses to sodium zirconium cyclosilicate in hyperkalemic hemodialysis patients: post-hoc analysis of DIALIZE
}

Steven Fishbane ${ }^{1 *}$, Martin Ford ${ }^{2,3}$, Masafumi Fukagawa ${ }^{4} \mathbb{0}$, Kieran McCafferty ${ }^{5}$ D, Anjay Rastogi ${ }^{6}$, Bruce Spinowitz ${ }^{7}$, Konstantin Staroselskiy ${ }^{8}$, Konstantin Vishnevskiy ${ }^{9}$, Vera Lisovskaja ${ }^{10}$, Ayman Al-Shurbaji ${ }^{11}$, Nicolas Guzman ${ }^{12}$ and Sunil Bhandari ${ }^{13}$

\begin{abstract}
Background: Sodium zirconium cyclosilicate (SZC) is an effective and well-tolerated treatment for hyperkalemia in maintenance hemodialysis patients. In post-hoc analyses of the phase 3b DIALIZE study, we examined the spectrum of potassium responses to SZC.

Methods: Post-hoc analyses with SZC and placebo included: the number of long interdialytic interval (LIDI) visits during the 4-week evaluation period where patients attained pre-dialysis serum potassium $\left(\mathrm{sK}^{+}\right)$concentrations of 4.0-5.0 and $4.0-5.5 \mathrm{mmol} / \mathrm{L}$; potassium gradient (the difference between pre-dialysis $\mathrm{sK}^{+}$and dialysate potassium) at days $36,43,50$, and 57 , and change from baseline to the end of treatment (EOT) using categories of potassium gradient ( 1 to $<2,2$ to $<3,3$ to $<4$, and $\geq 4 \mathrm{mmol} / \mathrm{L})$.

Results: A greater proportion of patients achieved the ranges of pre-dialysis $\mathrm{SK}^{+}$concentration with $\mathrm{SZC}$ versus placebo for $\geq 1, \geq 2, \geq 3$, and 4 LIDI visits over 4 weeks; 23.7 and $48.5 \%$ of patients in the SZC group achieved pre-dialysis sk ${ }^{+}$ concentrations of $4.0-5.0$ and $4.0-5.5 \mathrm{mmol} / \mathrm{L}$, respectively, at all $4 \mathrm{LIDI}$ visits. Baseline mean potassium gradient was similar with SZC and placebo. At day 57, mean (standard deviation) potassium gradient was $2.78(0.08) \mathrm{mmol} / \mathrm{L}$ with SZC and $3.52(0.08) \mathrm{mmol} / \mathrm{L}$ with placebo; mean difference $(95 \%$ confidence interval) was $-0.74 \mathrm{mmol} / \mathrm{L}(-0.97$ to -0.52$)$. A greater reduction in potassium gradient category from baseline towards lower-risk categories at EOT was observed with SZC versus placebo.
\end{abstract}

Conclusions: These analyses expand our knowledge of the spectrum of potassium responses with SZC in hyperkalemic hemodialysis patients.

Trial registration: NCT03303521.

Keywords: Hemodialysis, Chronic kidney disease, Potassium, Hyperkalemia, Sodium zirconium cyclosilicate

*Correspondence: Sfishbane@northwell.edu

1 Department of Medicine, Zucker School of Medicine at Hofstra/

Northwell, 100 Community Dr, Great Neck, NY 11021, USA

Full list of author information is available at the end of the article

\section{Background}

Patients with end-stage kidney disease (ESKD) have severely reduced renal potassium excretion. Excessively high serum potassium $\left(\mathrm{sK}^{+}\right)$is known to promote ventricular arrhythmias and cardiac death; however, even modest increases, such as $>5.5 \mathrm{mmol} / \mathrm{L}$, are associated with increased all-cause mortality and hospitalization [1-4]. 
Patients with ESKD require dialysis to remove accumulated potassium, with a goal of maintaining or restoring $\mathrm{sK}^{+}$to within the normal range. Maintenance hemodialysis is typically performed three times weekly, with two 1-day intervals (i.e., the short interdialytic interval [SIDI]) and one 2-day interval (the long interdialytic interval [LIDI]) between dialysis sessions [5]. During dialysis, potassium has the potential to move freely across the dialyzer membrane, typically down a concentration gradient from a patient's blood into the dialysate [6]. Therefore, dialysate potassium $\left(\mathrm{dK}^{+}\right)$concentration is a modifiable factor that affects the $\mathrm{sK}^{+}$concentration achieved during hemodialysis $[7,8]$. Studies to date on the impact of low $\mathrm{dK}^{+}$baths (typically defined as $0-1 \mathrm{mmol} / \mathrm{L}$ ) on hemodialysis outcomes have yielded contrasting results. Some studies have suggested no increased risk with low $\mathrm{dK}^{+}$baths $[1,9]$, while others have reported an increased risk of mortality, sudden death, or sudden cardiac arrest [4,10-13].

The potassium gradient results from the difference between a patient's $\mathrm{sK}^{+}$and $\mathrm{dK}^{+}$concentrations. A low gradient among patients with high $\mathrm{sK}^{+}$may result in insufficient potassium removal during dialysis, which is associated with a greater risk of hyperkalemia and increased mortality $[1,4,13]$. Dialysis with a high gradient, resulting from a high $\mathrm{sK}^{+}$and/or low $\mathrm{dK}^{+}$, leads to greater removal of potassium than with a lower gradient [7] and has utility in controlling hyperkalemia among patients with high $\mathrm{sK}^{+}[1]$. However, a high potassium gradient at the start of hemodialysis also causes more rapid fluxes of potassium and is associated with a greater risk of adverse events (AEs), such as cardiac arrhythmia, mortality, and hospitalization $[1,13-16]$. Therefore, physicians face a challenge to balance the need to remove sufficient potassium to avoid hyperkalemia, while minimizing the risk of AEs.

Hemodialysis patients with hyperkalemia often depend on additional strategies to manage hyperkalemia, typically including dietary counseling, therapies such as potassium binders or, in more extreme situations, longer or more frequent dialysis. Sodium zirconium cyclosilicate (SZC) is a novel, highly selective potassium binder that is not absorbed or metabolized by the body [17]. SZC preferentially captures potassium in the gastrointestinal lumen, thereby reducing potassium absorption and increasing potassium fecal excretion, and reducing sK ${ }^{+}$[17-19]. The efficacy and safety of SZC for the treatment of hyperkalemia have been demonstrated in phase 2 and 3 studies of non-dialysis populations with chronic kidney disease, heart failure, and diabetes [18-23], as well as in hemodialysis patients [24]. The phase 3b DIALIZE study demonstrated that SZC is an effective and well-tolerated treatment for hyperkalemia in patients with ESKD undergoing maintenance hemodialysis [24]. Overall, $41.2 \%$ of patients receiving SZC and $1.0 \%$ of patients receiving placebo were deemed to be treatment responders [24].
Here, we report the results of post-hoc analyses of the DIALIZE data performed to further examine the spectrum of potassium responses to SZC, in terms of $\mathrm{sK}^{+}$control and potassium gradient, in hyperkalemic hemodialysis patients.

\section{Methods}

\section{Study design and patients}

The full details of the DIALIZE study (NCT03303521) have been presented previously [24]. Briefly, DIALIZE was a randomized, double-blind, placebo-controlled, phase 3b study conducted across Japan, Russia, the US, and the UK. The study consisted of a 1-week screening period, an 8-week treatment period comprising 4 weeks for SZC dose titration and 4 weeks for evaluation on stable dose, and a 2-week follow-up period. Patients were randomized 1:1 to receive orally a starting dose of $5 \mathrm{~g}$ of SZC or placebo once daily on non-dialysis days (4days/week). All patients received hemodialysis three times weekly and routine dietary counseling as per local guidelines, including dietary potassium restriction. During dose titration, doses of SZC and placebo were adjusted weekly over 4weeks to achieve and maintain a pre-dialysis $\mathrm{sK}^{+}$concentration of $4.0-5.0 \mathrm{mmol} / \mathrm{L}$ after the LIDI. Doses of SZC and placebo were titrated in $5 \mathrm{~g}$ increments to a maximum dose of $15 \mathrm{~g}$ once daily on non-dialysis days (4 days/week).

Eligible patients were adults aged $\geq 18$ years with ESKD who were managed for $\geq 3$ months before randomization by hemodialysis three times weekly. During screening, patients were required to have hyperkalemia despite maintenance hemodialysis, defined as pre-dialysis $\mathrm{sK}^{+}>5.4 \mathrm{mmol} / \mathrm{L}$ after the LIDI on day -7 and pre-dialysis $\mathrm{sK}^{+}>5.0 \mathrm{mmol} / \mathrm{L}$ after $\geq 1$ SIDI on days -5 and -3 .

\section{Procedures}

Samples of $\mathrm{sK}^{+}$were measured using central laboratory assessment and a point-of-care i-STAT device (Abbott Point of Care, Inc., Princeton, NJ, USA). All dose adjustments were based on pre-dialysis $\mathrm{sK}^{+}$measured by i-STAT. Central laboratory samples were obtained throughout the study (both pre- and post-dialysis at LIDI visits, and only pre-dialysis at SIDI visits).

Prescription of $\mathrm{dK}^{+}$was recorded at randomization, during dose titration and at weekly intervals during the evaluation period. For pre-dialysis $\mathrm{sK}^{+}$concentrations $<4.0 \mathrm{mmol} / \mathrm{L}$, subsequent adjustments in $\mathrm{dK}^{+}$concentration could be made according to locally accepted clinical practice patterns guided by the investigator's clinical judgment. For centers that modified $\mathrm{dK}^{+}$concentration when pre-dialysis $\mathrm{sK}^{+}$concentration decreased, $\mathrm{dK}^{+}$concentration could be increased by 0.5 or $1.0 \mathrm{mmol} / \mathrm{L}$ if pre-dialysis $\mathrm{sK}^{+}$was $<4.0 \mathrm{mmol} / \mathrm{L}$. If $\mathrm{dK}^{+}$concentration could no longer be increased during the treatment 
period (e.g. the $\mathrm{dK}^{+}$concentration was $4.0 \mathrm{mmol} / \mathrm{L}$ ), the dose of SZC could be decreased by $5 \mathrm{~g}$ or held if the patient was already taking the minimum dose $(5 \mathrm{~g})$. For sites where local clinical practice did not include increasing the $\mathrm{dK}^{+}$ concentration when pre-dialysis $\mathrm{sK}^{+}$fell, the dose of SZC or placebo could be decreased by $5 \mathrm{~g}$ or held if the patient was already taking the minimum dose.

\section{Post-hoc analysis}

In these post-hoc analyses, we assessed the number of LIDI visits during the evaluation period (days 36, 43, 50, 57) where patients attained pre-dialysis $\mathrm{sK}^{+}$ranges with $\mathrm{SZC}$ and placebo. Pre-dialysis $\mathrm{sK}^{+}$ranges analyzed were $4.0-5.0 \mathrm{mmol} / \mathrm{L}$ and an extended range of $4.0-5.5 \mathrm{mmol} / \mathrm{L}$; the latter reflected a range deemed to be acceptable in clinical practice, as $\mathrm{sK}^{+}$concentrations $>5.5 \mathrm{mmol} / \mathrm{L}$ are associated with increased hospitalization and mortality $[1,2,4]$. Furthermore, we assessed the potassium gradient at days $36,43,50$, and 57 with SZC and placebo, as well as the change from baseline to the end of the evaluation period (day 57) using a categorization of potassium gradient ( 1 to $<2,2$ to $<3,3$ to $<4$, and $\geq 4 \mathrm{mmol} / \mathrm{L}$ ). A potassium gradient of 2 to $<3 \mathrm{mmol} / \mathrm{L}$ was determined to be of lower risk, based on a recent report where this range was used as the referent potassium gradient category; categories above this were associated with hospitalization and emergency department visits [16].

\section{Statistical analysis}

All statistical analyses were performed using SAS v9.4 (SAS Institute, Cary, NC, USA). The number of LIDI visits during the evaluation period where patients achieved $\mathrm{sK}^{+}$ranges (4.0-5.0 or $4.0-5.5 \mathrm{mmol} / \mathrm{L}$ ) was summarized descriptively using percentages. Patients receiving rescue therapy were included in the analysis. No imputation of missing data was conducted. For potassium gradient, at each visit all estimates and $95 \%$ confidence intervals (CIs) in the evaluation period were obtained from a linear model with gradient as response and treatment as the single covariate. For days $36,43,50$, and 57 , the mean and standard deviation (SD) for each treatment group are the least-squares mean from this model, which was fitted for each visit separately. For change from baseline to the end of the evaluation period in categories of potassium gradient, baseline was defined as visit 1 (day -7$)$, and percentages were calculated using the number of patients with an available baseline value.

\section{Results}

\section{Patients}

In DIALIZE, 97 and 99 patients were randomized to receive SZC and placebo, respectively. At baseline, 58.7\% of patients were men, mean (SD) age was 58.1 (13.7) years, and mean (SD) weight was 71.0 (19.1) kg (Table 1).
Most patients were White (52.0\%), Asian (33.7\%), or black or African American (9.7\%; Table 1).

\section{Control of hyperkalemia}

Baseline mean (SD) pre-dialysis $\mathrm{sK}^{+}$was comparable for SZC and placebo: $5.8(0.6) \mathrm{mmol} / \mathrm{L}$ versus 5.9 (0.6) $\mathrm{mmol} / \mathrm{L}$, respectively (Table 1 ). SZC was associated with a greater proportion of patients achieving pre-dialysis $\mathrm{sK}^{+}$of $4.0-5.0 \mathrm{mmol} / \mathrm{L}$ versus placebo for $\geq 1, \geq 2, \geq 3$, and 4 LIDI visits during the evaluation period (Fig. 1a). Overall, $78.4 \%$ of patients receiving SZC achieved pre-dialysis $\mathrm{sK}^{+}$of $4.0-5.0 \mathrm{mmol} / \mathrm{L}$ at 1

Table 1 Baseline patient characteristics

\begin{tabular}{|c|c|c|}
\hline Characteristic & $\mathrm{SZC}(n=97)$ & Placebo $(n=99)$ \\
\hline Age, years, mean (SD) & $55.7(13.8)$ & $60.4(13.2)$ \\
\hline Sex, male, $n(\%)$ & $57(58.8)$ & $58(58.6)$ \\
\hline \multicolumn{3}{|l|}{ Race, $n(\%)$} \\
\hline White & $50(51.5)$ & $52(52.5)$ \\
\hline Black or African American & $11(11.3)$ & $8(8.1)$ \\
\hline Asian & $33(34.0)$ & $33(33.3)$ \\
\hline American Indian or Alaska Native & $1(1.0)$ & $2(2.0)$ \\
\hline Other & $2(2.1)$ & $4(4.0)$ \\
\hline Height, cm, mean (SD) & $166.4(9.9)$ & $165.1(9.2)$ \\
\hline Weight, kg, mean (SD) & $72.0(22.0)$ & $70.0(15.9)$ \\
\hline $\mathrm{BMI}, \mathrm{kg} / \mathrm{m}^{2}$, mean (SD) & $26.9(7.1)$ & $26.7(5.4)$ \\
\hline $\begin{array}{l}\text { Pre-dialysis serum potassium concentration, } \\
\mathrm{mmol} / \mathrm{L} \text {, mean }(\mathrm{SD})^{\mathrm{a}}\end{array}$ & $5.8(0.6)$ & $5.9(0.6)$ \\
\hline \multicolumn{3}{|l|}{ Dialysis history } \\
\hline Vintage, years, mean (SD) & $8.0(6.1)$ & $7.8(7.6)$ \\
\hline \multicolumn{3}{|l|}{ Access type, $n(\%)$} \\
\hline Arteriovenous fistula & $84(87.5)$ & $90(90.9)$ \\
\hline Arteriovenous graft & $7(7.3)$ & $3(3.0)$ \\
\hline Tunneled central venous catheter & $4(4.2)$ & $6(6.1)$ \\
\hline Other & $1(1.0)$ & $0(0.0)$ \\
\hline Total & $96(100.0)$ & $99(100.0)$ \\
\hline \multicolumn{3}{|l|}{ Dialysis adequacy } \\
\hline spKt/N, mean (SD) & $1.7(0.3)$ & $1.7(0.4)$ \\
\hline Urea removal rate, $\%$, mean (SD) & $72.9(6.7)$ & $74.6(5.6)$ \\
\hline Dialysate flow, ml/min, mean (SD) & $512.0(162.8)$ & $538.5(136.0)$ \\
\hline \multicolumn{3}{|l|}{ Dialysis potassium concentration, $\mathrm{mmol} / \mathrm{L}$} \\
\hline Mean (SD) & $2.26(0.49)$ & $2.26(0.47)$ \\
\hline Minimum, maximum & 1.0 to 3.0 & 1.0 to 3.0 \\
\hline Blood flow, ml/min, mean (SD) & $322.0(110.7)$ & $318.5(96.3)$ \\
\hline
\end{tabular}

Republished with the permission of American Society of Nephrology, from A Phase 3b, Randomized, Double-Blind, Placebo-Controlled Study of Sodium Zirconium Cyclosilicate for Reducing the Incidence of Predialysis Hyperkalemia, Fishbane S et al. JASN. Sep 2019;30(9):1723-1733; permission conveyed through Copyright Clearance Center, Inc.

$B M I$ body mass index, SD standard deviation, spKt/V single-pool Kt/V, SZC sodium zirconium cyclosilicate

a Visit 4 (Day 1) 
of the 4 LIDIs during the evaluation period, versus $26.3 \%$ of patients receiving placebo (Fig. 1a). Furthermore, 41.2 and $23.7 \%$ of patients receiving SZC achieved pre-dialysis $\mathrm{sK}^{+}$of $4.0-5.0 \mathrm{mmol} / \mathrm{L}$ at 3 out of 4 and all 4 LIDI visits, respectively, versus 1.0 and $0 \%$ of patients receiving placebo, respectively (Fig. 1a). Similar findings were observed using the extended pre-dialysis $\mathrm{sK}^{+}$range of $4.0-5.5 \mathrm{mmol} / \mathrm{L}$, although greater proportions of patients achieved the range (Fig. 1b). Overall, 69.1 and $48.5 \%$ of patients receiving SZC achieved pre-dialysis $\mathrm{sK}^{+}$of $4.0-5.5 \mathrm{mmol} / \mathrm{L}$ at 3 out of 4 and all 4 LIDI visits, respectively, versus 19.2 and $5.1 \%$ of patients receiving placebo, respectively (Fig. 1b).

\section{Dialysate potassium}

Baseline mean (SD) $\mathrm{dK}^{+}$concentration was comparable for SZC and placebo: $2.26(0.49) \mathrm{mmol} / \mathrm{L}$ (minimum, maximum: 1.0 to 3.0$)$ versus $2.26(0.47) \mathrm{mmol} / \mathrm{L}$ (minimum, maximum: 1.0 to 3.0 ), respectively (Table 1 ). Despite significantly reduced pre-dialysis $\mathrm{sK}^{+}$, mean $\mathrm{dK}^{+}$concentration was largely unchanged at the end of treatment (EOT). At day 57, mean (SD) $\mathrm{dK}^{+}$concentration with SZC was $2.28(0.47) \mathrm{mmol} / \mathrm{L}$ (minimum, maximum: 1.0 to 3.0$)$ and with placebo was 2.25 (0.48) $\mathrm{mmol} / \mathrm{L}$ (minimum, maximum: 1.0 to 3.0 ). Concentration of $\mathrm{dK}^{+}$was increased in only $2(2.3 \%)$ patients receiving SZC and 1 (1.1\%) patient receiving placebo.

\section{Potassium gradient}

Baseline (visit 1, day -7) mean (SD) potassium gradient was comparable for SZC and placebo: $3.78(0.59) \mathrm{mmol} / \mathrm{L}$ versus $3.73(0.64) \mathrm{mmol} / \mathrm{L}$, respectively. During the evaluation period, potassium gradient was lower with SZC versus placebo at each of the 4 LIDI visits (Fig. 2). At day 57, mean (SD) potassium gradient was $2.78(0.08)$ $\mathrm{mmol} / \mathrm{L}$ with SZC and $3.52(0.08) \mathrm{mmol} / \mathrm{L}$ with placebo; mean difference of $-0.74 \mathrm{mmol} / \mathrm{L}(95 \% \mathrm{CI}-0.97$ to -0.52 ; Fig. 2).

At baseline, 12, 45, and 38 patients receiving SZC had potassium gradients of 2 to $<3,3$ to $<4$, and $\geq 4 \mathrm{mmol} / \mathrm{L}$, respectively. In the placebo group, 16,50 , and 32 patients had baseline potassium gradients of 2 to $<3,3$ to $<4$, and $\geq 4 \mathrm{mmol} / \mathrm{L}$, respectively. No patient in either treatment group had a baseline potassium gradient of 1 to $<2 \mathrm{mmol} / \mathrm{L}$. A greater reduction in potassium gradient categories from baseline to EOT (day 57) was observed with SZC than with placebo (Fig. 3); furthermore, the magnitude of reduction was dependent on baseline potassium gradient (Fig. 3). With SZC, 55.6\% $(n=25 / 45)$ and $29.0 \%$ ( $n=11 / 38)$ of patients with baseline potassium gradients of 3 to $<4$ and $\geq 4 \mathrm{mmol} / \mathrm{L}$, respectively, had reductions to a lower risk gradient category of $2-3 \mathrm{mmol} / \mathrm{L}$ (Fig. 3). This compared with $10 \%(n=5 / 50)$ and $3.1 \%(n=1 / 32)$, respectively, of patients receiving placebo (Fig. 3), suggestive of regression to the mean in these patients with a higher baseline potassium gradient. In the SZC group, no patients with a baseline potassium gradient of 2 to $<3 \mathrm{mmol} / \mathrm{L}(n=12)$ had an increase in gradient to a higher risk category; $41.7 \%$ $(n=5 / 12)$ of patients remained as 2 to $<3 \mathrm{mmol} / \mathrm{L}$ and $41.7 \%(n=5 / 12)$ decreased to 1 to $<2 \mathrm{mmol} / \mathrm{L}$ (data were missing for 2 patients; Fig. 3). In the 16 placebo patients who had a baseline potassium gradient of 2 to $<3 \mathrm{mmol} / \mathrm{L}$, $43.8 \%(n=7 / 16)$ had an increase in gradient to a higher risk category of 3 to $<4 \mathrm{mmol} / \mathrm{L}$, while $43.8 \%(n=7 / 16)$ remained the same (data were missing for 2 patients; Fig. 3).

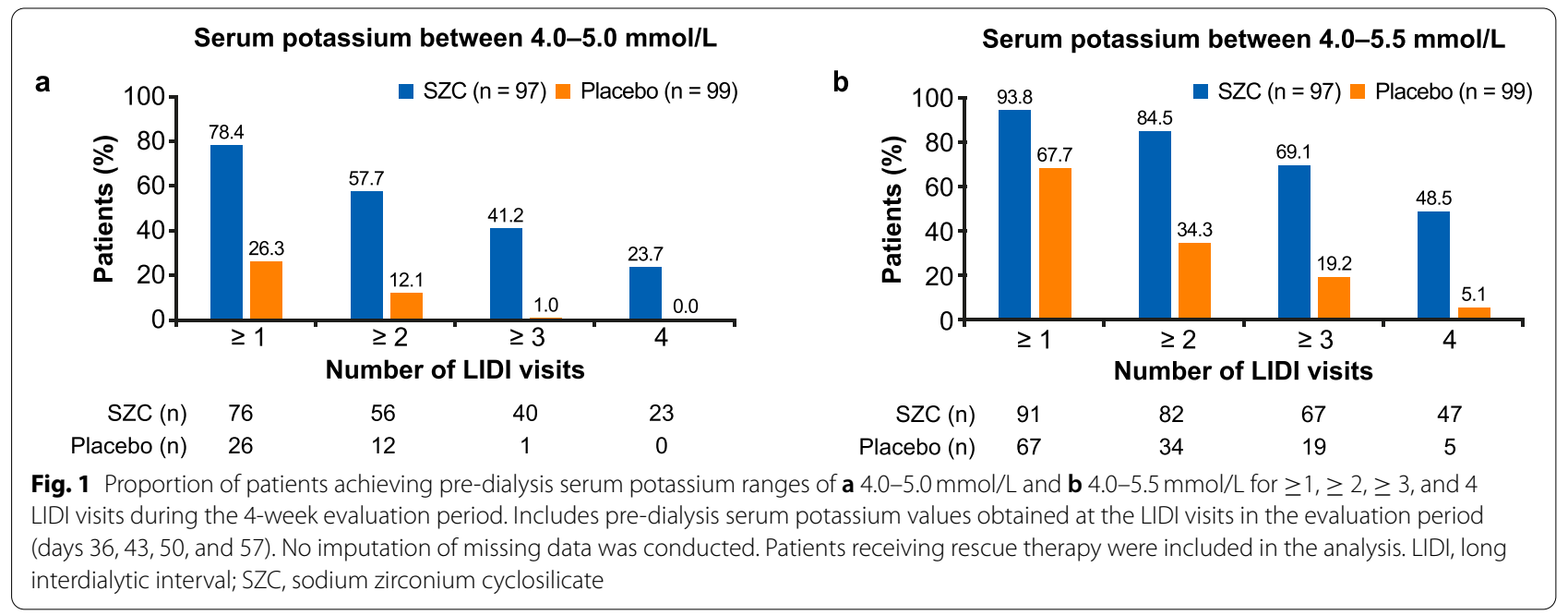




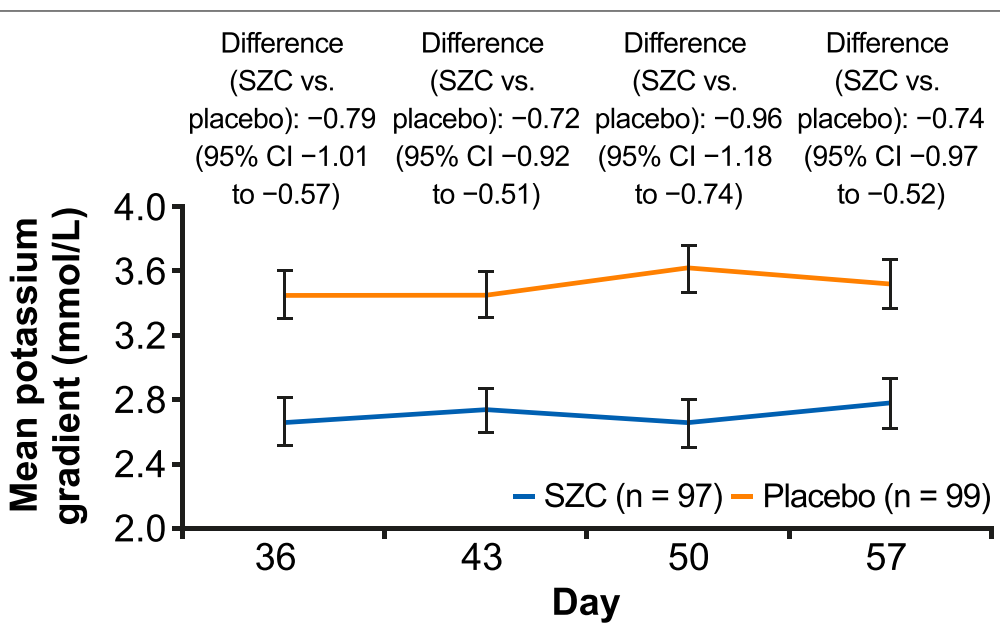

Fig. 2 Mean serum potassium to dialysate potassium gradient (mmol/L) during the 4-week evaluation period. Baseline (visit 1, day -7) mean (SD) potassium gradient was comparable between the treatment arms: SZC $3.78(0.59) \mathrm{mmol} / \mathrm{L}$ versus placebo $3.73(0.64) \mathrm{mmol} / \mathrm{L}$. Error bars represent 95\% Cls. All estimates and 95\% Cls in the 4-week evaluation period are obtained from a linear model with gradient as response and treatment as the single covariate. The mean for each treatment group is the least-squares mean from this model. The model was fitted for each visit separately. Cl, confidence interval; SD, standard deviation; SZC, sodium zirconium cyclosilicate

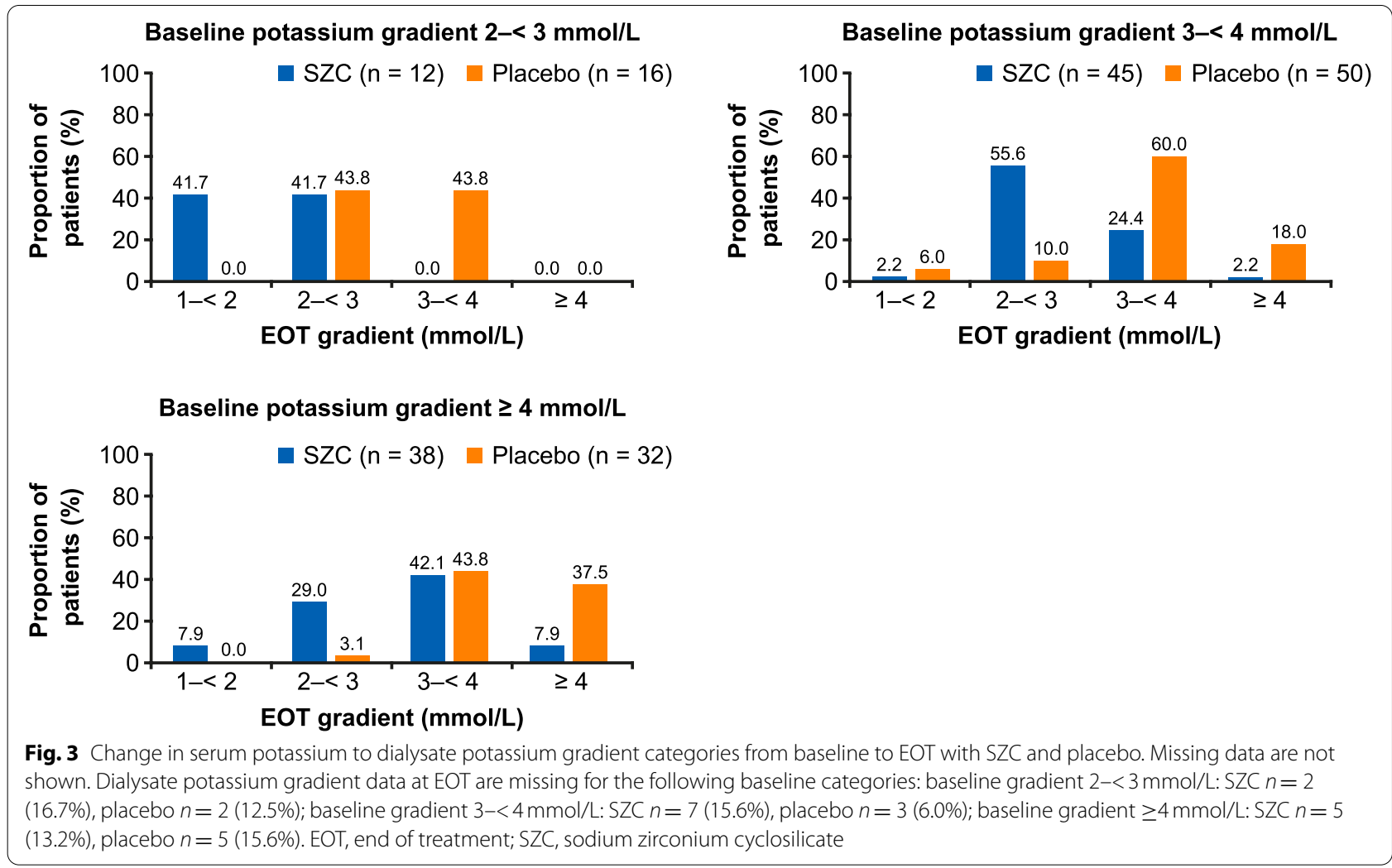

\section{Discussion}

Recently, Kidney Disease: Improving Global Outcomes (KDIGO) recommended further research determining the efficacy of newer agents in patients with ESKD receiving maintenance hemodialysis [25]. We used data from the phase 3b DIALIZE study to further investigate the spectrum of potassium responses with SZC in maintenance hemodialysis patients with hyperkalemia. SZC was associated with 
a greater proportion of patients achieving clinically recommended or acceptable pre-dialysis $\mathrm{sK}^{+}$ranges and lower potassium gradient during the evaluation period versus placebo.

Our findings extend those previously reported in the phase 3b DIALIZE study regarding control of $\mathrm{sK}^{+}$with SZC [24]. We assessed control of hyperkalemia using a pre-dialysis sK ${ }^{+}$range of $4.0-5.0 \mathrm{mmol} / \mathrm{L}$ and an extended range of $4.0-5.5 \mathrm{mmol} / \mathrm{L}$. Although UK clinical practice guidelines recommend maintaining a pre-dialysis $\mathrm{sK}^{+}$ concentration of $4.0-6.0 \mathrm{mmol} / \mathrm{L}$ [26], previous analyses have shown that $\mathrm{sK}^{+}$concentrations of $\geq 5.6 \mathrm{mmol} / \mathrm{L}$ are associated with increased all-cause and cardiovascular mortality $[1,4,27]$, and $\geq 5.5 \mathrm{mmol} / \mathrm{L}$ is associated with hospitalization [2]. For many physicians and patients, achieving and maintaining a pre-dialysis $\mathrm{sK}^{+}$concentration of $4.0-5.5 \mathrm{mmol} / \mathrm{L}$ would be considered a successful response in hemodialysis patients with hyperkalemia, while preventing patients from being exposed to the risks associated with $\mathrm{sK}^{+}>5.5 \mathrm{mmol} / \mathrm{L}$. In our analyses, regardless of the $\mathrm{sK}^{+}$range used, SZC was associated with greater control of $\mathrm{sK}^{+}$versus placebo. Using the extended range of $4.0-5.5 \mathrm{mmol} / \mathrm{L}$, nearly half of the patients receiving $\mathrm{SZC}$ achieved and maintained the $\mathrm{sK}^{+}$range at all 4 LIDI visits over a 4-week period. Some reduction from baseline in $\mathrm{sK}^{+}$was observed with placebo, which may be attributable to some patients having temporary increases in $\mathrm{sK}^{+}$or to a change in patient behavior such as an increased compliance to diet restrictions.

Reports suggest that a high potassium gradient at the start of hemodialysis is associated with risk of AEs, such as cardiac arrhythmia, mortality, and hospitalization [1, 13-16], probably related to more rapid and larger potassium fluxes during the dialysis session. For instance, Brunelli et al. used a reference potassium gradient of 2 to $<3 \mathrm{mmol} / \mathrm{L}$, and observed an 8,26 , and $59 \%$ higher adjusted risk of hospitalization following dialysis with gradient categories of 3 to $<4,4$ to $<5$, and $\geq 5 \mathrm{mmol} / \mathrm{L}$, respectively [16]. In addition, the authors observed an increased risk of emergency department visits following dialysis of 6,17 , and $54 \%$ with potassium gradient categories of 3 to $<4,4$ to $<5$, and $\geq 5 \mathrm{mmol} / \mathrm{L}$, respectively, versus 2 to $<3 \mathrm{mmol} / \mathrm{L}$. Although there was no significant association between risk of mortality and higher potassium gradient, the authors observed a non-significant trend towards a greater risk of cardiovascular hospitalization with $\geq 5 \mathrm{mmol} / \mathrm{L}$ versus 2 to $<3 \mathrm{mmol} / \mathrm{L}$ [16]. This led the authors to suggest that the observed associations may be driven by cardiac arrhythmias and their immediate consequences [16]. As a reduction in potassium gradient is often recommended $[14,15]$, the reduction in potassium gradient to $<3.0 \mathrm{mmol} / \mathrm{L}$ with SZC observed in our analyses could potentially lower the risks associated with these factors, although further investigation is required to confirm this.

Practice patterns of $\mathrm{dK}^{+}$concentration are known to vary globally, reflecting the lack of consensus and guidelines on ideal practice. In an analysis of the Dialysis Outcomes and Practice Patterns Study, $\mathrm{dK}^{+}$ of $2.0-2.5 \mathrm{mmol} / \mathrm{L}$ was most commonly used worldwide, and was prescribed to $75 \%$ of patients in the US and $>99 \%$ of patients in Japan [4]. In the US, patients are typically prescribed a $\mathrm{dK}^{+}$of $2.0-4.0 \mathrm{mmol} / \mathrm{L}[4,16,28]$, with approximately $3 \%$ of patients receiving $1.0-1.5 \mathrm{mmol} / \mathrm{L}$ [4]. Recently, a trend has been observed for steadily increasing $\mathrm{dK}^{+}$concentrations in North America, Europe, Australia, and New Zealand [4], possibly resulting from increased interest in the impact of $\mathrm{dK}^{+}$on hemodialysis outcomes. Several reports have shown that $\mathrm{dK}^{+}$concentrations of $0-1,<1.5$, or $<2 \mathrm{mmol} / \mathrm{L}$ are associated with a higher risk of cardiac arrest, sudden death, and all-cause mortality among hemodialysis patients than with higher $\mathrm{dK}^{+}[10-12]$. Furthermore, Karaboyas et al. showed that a $\mathrm{dK}^{+}$concentration of $1.0-1.5 \mathrm{mmol} / \mathrm{L}$ is associated with a higher risk of mortality than with $2.0-2.5 \mathrm{mmol} / \mathrm{L}$ [4]. Meanwhile, no meaningful differences in clinical outcomes were observed with a $\mathrm{dK}^{+}$concentration of 3.0 versus $2.0 \mathrm{mmol} / \mathrm{L}[4,13]$. Despite these findings, $\mathrm{dK}^{+}$prescriptions of $1.0-1.5 \mathrm{mmol} / \mathrm{L}$ or lower are still used; e.g. $1.0-1.5 \mathrm{mmol} / \mathrm{L}$ is used by $62 \%$ of patients in Spain and 9\% of patients in the Gulf Cooperation Council [4]. Indeed, $\mathrm{dK}^{+}$concentration should be no lower than is necessary to achieve potassium control, and recent publications have recommended avoiding $\mathrm{dK}^{+}$of $<2.0 \mathrm{mmol} / \mathrm{L}[4,12,28-31]$.

Approaches other than modifying hemodialysis factors, such as pharmacological options and education on dietary potassium sources, may merit further attention to improve hemodialysis outcomes $[4,13,16,28]$. Concentrations of $\mathrm{sK}^{+}$are typically monitored once a month in clinical practice, but more frequent monitoring of pre-dialysis $\mathrm{sK}^{+}$may allow appropriate adjustment of $\mathrm{dK}^{+}$concentration $[1,12,31]$. In DIALIZE, $\mathrm{dK}^{+}$modification was based on investigator's choice and locally accepted clinical practice [24]. As demonstrated in the present analyses, the potential beneficial effect on potassium gradient is due to the reduction in pre-dialysis $\mathrm{sK}^{+}$with $\mathrm{SZC}$, since so few patients had an increase in $\mathrm{dK}^{+}$during the study. In the long-term, this may result in the ability to relax dietary potassium restrictions allowing a diet that is richer in nutrients and fiber, as well as a potential reduction in additional acute dialysis treatments, which could improve patients' quality of life; however, this requires further investigation.

The present analyses have several limitations. Although the analyses provide interesting findings requiring further study, they are post-hoc in nature and were not prespecified; therefore, the results are exploratory and 
hypothesis-generating. Patient numbers within the potassium gradient categories were small, limiting the interpretation of these findings. Target $\mathrm{sK}^{+}$varies in clinical practice according to local guidelines; as such, the ranges analyzed may not be applicable worldwide. The changes in potassium gradient seen were predominantly due to reduction in pre-dialysis $\mathrm{sK}^{+}$with $\mathrm{SZC}$, and so the potential benefit of increasing $\mathrm{dK}^{+}$baths could not be explored. Finally, clinical characteristics at baseline that may contribute to control of hyperkalemia or reduction in potassium gradient were not explored. However, the analyses presented here have several strengths. Specifically, the analyses are derived from a randomized controlled trial with a robust methodology that included blinding, multiple study centers, and repeated measures during several LIDI visits.

\section{Conclusions}

In conclusion, these analyses expand our knowledge of the spectrum of potassium response with SZC in maintenance hemodialysis patients with hyperkalemia. Our findings suggest that treatment with SZC improves control of hyperkalemia in maintenance hemodialysis patients with hyperkalemia. A reduction in potassium gradient towards values below the reported higher risk of $>3.0 \mathrm{mmol} / \mathrm{L}$ with $\mathrm{SZC}$ was observed largely without changing $\mathrm{dK}^{+}$. Further investigation is required to determine whether this finding could potentially modify the risks associated with a high potassium gradient.

\section{Abbreviations \\ AE: Adverse event; $\mathrm{Cl}$ : Confidence interval; $\mathrm{dK}^{+}$: Dialysate potassium; EOT: End of treatment; ESKD: End-stage kidney disease; KDIGO: Kidney Disease: Improving Global Outcomes; LIDI: Long interdialytic interval; SD: Standard deviation; SIDI: Short interdialytic interval; SK $^{+}$: Serum potassium; SZC: Sodium zirconium cyclosilicate.}

\section{Acknowledgments}

The authors would like to thank the patients, their families, and all investigators involved in the DIALIZE study, the dialysis services and research staff in each participating center, as well as the members of the data monitoring committee: David Charytan, MD, Charles Herzog, MD, and David Wheeler, MD. Development of this manuscript was supported by AstraZeneca. Medical writing support was provided by Shaun W. Foley, BSC (Hons), CMPP ${ }^{\mathrm{TM}}$, and editorial support was provided by Sinead Stewart, both of Core, London, UK, supported by AstraZeneca according to Good Publication Practice guidelines (https://www.acpjournals. org/doi/10.7326/M15-0288). The sponsor was involved in the study design and collection, analysis, and interpretation of data, as well as data checking of information provided in the manuscript. Ultimate responsibility for opinions, conclusions, and data interpretation lies with the authors. Parts of these data were presented as an oral presentation at Kidney Week 2019, Washington, DC, November 5-10, 2019.

\section{Authors' contributions}

All authors contributed to the data interpretation, critically reviewed the manuscript, approved the final version, and accept accountability for the overall work.
Funding

Development of this manuscript was supported by AstraZeneca.

\section{Availability of data and materials}

These post-hoc analyses were derived from the DIALIZE study (NCT03303521); the full details have been presented previously [24]. Data underlying the findings described in this manuscript may be requested in accordance with AstraZeneca's data sharing policy described at https://astrazenecagroup-dt. pharmacm.com/DT/Home by accessing www.vivli.org.

\section{Declarations}

\section{Ethics approval and consent to participate}

The DIALIZE study was performed in accordance with the Declaration of Helsinki, the International Council for Harmonisation, and Good Clinical Practice. The informed consent form, protocol, and amendments were approved by an independent ethics committee or institutional review board for each center before study initiation. All participants provided written informed consent.

\section{Consent for publication}

Not applicable.

\section{Competing interests}

SF received research support and consulting fees from AstraZeneca. MFord received travel support from Amgen and AstraZeneca, and is an advisory board member for AstraZeneca. MFukagawa received consulting fees and lectures fees from AstraZeneca Japan. KM is an academic grant holder and advisory board member for AstraZeneca. AR received research or travel support from and/or is a speaker, consultant, or advisory board member for AstraZeneca, Relypsa, Fresenius Medical Care, Sanofi, Kadmon, AMAG, Otsuka, Genzyme, GSK, Omerus, Janssen, Reata Pharmaceuticals, Ironwood, and Amgen. BS received research grants, lecture fees and/or consulting fees from AstraZeneca, Akebia, Reata Pharmaceuticals, and Fresenius Medical Care. KS received research support from AstraZeneca. KV received research support from AstraZeneca. VL, AAS, and NG are employees of AstraZeneca. SB has given lectures and participated in an advisory board for AstraZeneca, has given lectures sponsored by Vifor Pharma, and has received travel support from AstraZeneca and Vifor Pharma.

\section{Author details}

${ }^{1}$ Department of Medicine, Zucker School of Medicine at Hofstra/Northwell, 100 Community Dr, Great Neck, NY 11021, USA. ² Department of Renal Medicine, King's College Hospital NHS Trust, London, UK. ${ }^{3}$ Faculty of Life Sciences and Medicine, King's College, London, UK. ${ }^{4}$ Division of Nephrology, Endocrinology and Metabolism, Department of Internal Medicine, Tokai University School of Medicine, Isehara, Japan. ${ }^{5}$ Department of Nephrology, Bart's Health NHS Trust, London, UK. ${ }^{6}$ UCLA CORE Kidney Program, University of California Los Angeles, Los Angeles, CA, USA. ${ }^{7}$ Department of Medicine, New York-Presbyterian Queens, Queens, NY, USA. ${ }^{8}$ Department \#2, B. Braun Avitum Russland Clinics, St Petersburg, Russia. ${ }^{9}$ Propedeutics of Internal Diseases Chair, First Pavlov State Medical University of St Petersburg, St Petersburg, Russia. ${ }^{10}$ Biometrics and Information, AstraZeneca BioPharmaceuticals R\&D Gothenburg, Mölndal, Sweden. ${ }^{11}$ Global Medicines Development, AstraZeneca BioPharmaceuticals R\&D Gothenburg, Mölndal, Sweden. ${ }^{12}$ Global Medicines Development, AstraZeneca BioPharmaceuticals R\&D, Gaithersburg, MD, USA. ${ }^{13}$ Department of Renal and Transplant Medicine, Hull University Teaching Hospitals NHS Trust, Hull, UK

Received: 23 March 2021 Accepted: 14 September 2021 Published online: 08 February 2022

\section{References}

1. Kovesdy CP, Regidor DL, Mehrotra R, Jing J, McAllister CJ, Greenland $\mathrm{S}$, et al. Serum and dialysate potassium concentrations and survival in hemodialysis patients. Clin J Am Soc Nephrol. 2007;2(5):999-1007.

2. Brunelli SM, Du Mond C, Oestreicher N, Rakov V, Spiegel DM. Serum potassium and short-term clinical outcomes among hemodialysis 
patients: impact of the long interdialytic interval. Am J Kidney Dis. 2017;70(1):21-9

3. Genovesi S, Valsecchi MG, Rossi E, Pogliani D, Acquistapace I, De Cristofaro V, et al. Sudden death and associated factors in a historical cohort of chronic haemodialysis patients. Nephrol Dial Transplant. 2009;24(8):2529-36.

4. Karaboyas A, Zee J, Brunelli SM, Usvyat LA, Weiner DE, Maddux FW, et al. Dialysate potassium, serum potassium, mortality, and arrhythmia events in hemodialysis: results from the Dialysis Outcomes and Practice Patterns Study (DOPPS). Am J Kidney Dis. 2017;69(2):266-77.

5. Foley RN, Gilbertson DT, Murray T, Collins AJ. Long interdialytic interval and mortality among patients receiving hemodialysis. N Engl J Med. 2011:365(12):1099-107.

6. Agar BU, Culleton BF, Fluck R, Leypoldt JK. Potassium kinetics during hemodialysis. Hemodial Int. 2015;19(1):23-32.

7. Hou S, McElroy PA, Nootens J, Beach M. Safety and efficacy of low-potassium dialysate. Am J Kidney Dis. 1989;13(2):137-43.

8. Zehnder C, Gutzwiller JP, Huber A, Schindler C, Schneditz D. Low-potassium and glucose-free dialysis maintains urea but enhances potassium removal. Nephrol Dial Transplant. 2001:16(1):78-84

9. Al-Ghamdi G, Hemmelgarn B, Klarenbach S, Manns B, Wiebe N, Tonelli $M$, et al. Dialysate potassium and risk of death in chronic hemodialysis patients. J Nephrol. 2010;23(1):33-40.

10. Jadoul M, Thumma J, Fuller DS, Tentori F, Li Y, Morgenstern H, et al. Modifiable practices associated with sudden death among hemodialysis patients in the Dialysis Outcomes and Practice Patterns Study. Clin J Am Soc Nephrol. 2012;7(5):765-74.

11. Karnik JA, Young BS, Lew NL, Herget M, Dubinsky C, Lazarus JM, et al. Cardiac arrest and sudden death in dialysis units. Kidney Int. 2001;60(1):350-7.

12. Pun PH, Lehrich RW, Honeycutt EF, Herzog CA, Middleton JP. Modifiable risk factors associated with sudden cardiac arrest within hemodialysis clinics. Kidney Int. 2011;79(2):218-27.

13. Ferrey A, You AS, Kovesdy CP, Nakata T, Veliz M, Nguyen DV, et al. Dialysate potassium and mortality in a prospective hemodialysis cohort. Am J Nephrol. 2018;47(6):415-23.

14. Redaelli B, Locatelli F, Limido D, Andrulli S, Signorini MG, Sforzini S, et al. Effect of a new model of hemodialysis potassium removal on the control of ventricular arrhythmias. Kidney Int. 1996;50(2):609-17.

15. Santoro A, Mancini E, London G, Mercadal L, Fessy H, Perrone B, et al. Patients with complex arrhythmias during and after haemodialysis suffer from different regimens of potassium removal. Nephrol Dial Transplant. 2008;23(4):1415-21.

16. Brunelli SM, Spiegel DM, Du Mond C, Oestreicher N, Winkelmayer WC, Kovesdy CP. Serum-to-dialysate potassium gradient and its association with short-term outcomes in hemodialysis patients. Nephrol Dial Transplant. 2018;33(7):1207-14.

17. Stavros F, Yang A, Leon A, Nuttall M, Rasmussen HS. Characterization of structure and function of ZS-9, a $\mathrm{K}^{+}$selective ion trap. PLoS One. 2014;9(12):e114686-e.

18. Kosiborod M, Rasmussen HS, Lavin P, Qunibi WY, Spinowitz B, Packham $D$, et al. Effect of sodium zirconium cyclosilicate on potassium lowering for 28 days among outpatients with hyperkalemia: the HARMONIZE randomized clinical trial. JAMA. 2014;312(21):2223-33.

19. Ash SR, Singh B, Lavin PT, Stavros F, Rasmussen HS. A phase 2 study on the treatment of hyperkalemia in patients with chronic kidney disease suggests that the selective potassium trap, ZS-9, is safe and efficient. Kidney Int. 2015;88(2):404-11.

20. Anker SD, Kosiborod M, Zannad F, Piña IL, McCullough PA, Filippatos $G$, et al. Maintenance of serum potassium with sodium zirconium cyclosilicate (ZS-9) in heart failure patients: results from a phase 3 randomized, double-blind, placebo-controlled trial. Eur J Heart Fail. 2015;17(10):1050-6.

21. Packham DK, Rasmussen HS, Lavin PT, El-Shahawy MA, Roger SD, Block $\mathrm{G}$, et al. Sodium zirconium cyclosilicate in hyperkalemia. N Engl J Med. 2015:372(3):222-31

22. Spinowitz BS, Fishbane S, Pergola PE, Roger SD, Lerma EV, Butler J, et al. Sodium zirconium cyclosilicate among individuals with hyperkalemia: a 12-month phase 3 study. Clin J Am Soc Nephrol. 2019;14(6):798-809.

23. Roger SD, Spinowitz BS, Lerma EV, Singh B, Packham DK, Al-Shurbaji A, et al. Efficacy and safety of sodium zirconium cyclosilicate for treatment of hyperkalemia: an 11-month open-label extension of HARMONIZE. Am J Nephrol. 2019;50(6):473-80.

24. Fishbane S, Ford M, Fukagawa M, McCafferty K, Rastogi A, Spinowitz B, et al. A phase $3 \mathrm{~b}$, randomized, double-blind, placebo-controlled study of sodium zirconium cyclosilicate for reducing the incidence of predialysis hyperkalemia. J Am Soc Nephrol. 2019;30(9):1723-33.

25. Clase CM, Carrero J-J, Ellison DH, Grams ME, Hemmelgarn BR, Jardine MJ, et al. Potassium homeostasis and management of dyskalemia in kidney diseases: conclusions from a Kidney Disease: Improving Global Outcomes (KDIGO) controversies conference. Kidney Int. 2020;97(1):42-61.

26. Ashby D, Borman N, Burton J, Corbett R, Davenport A, Farrington K, et al. Renal association clinical practice guideline on haemodialysis. BMC Nephrol. 2019;20(1):379.

27. Yusuf AA, Hu Y, Singh B, Menoyo JA, Wetmore JB. Serum potassium levels and mortality in hemodialysis patients: a retrospective cohort study. Am J Nephrol. 2016:44(3):179-86.

28. Thornley-Brown D, Saha M. Dialysate content and risk of sudden cardiac death. Curr Opin Nephrol Hypertens. 2015;24(6):557-62.

29. Locatelli F, La Milia V, Violo L, Del Vecchio L, Di Filippo S. Optimizing haemodialysate composition. Clin Kidney J. 2015;8(5):580-9.

30. Hung AM, Hakim RM. Dialysate and serum potassium in hemodialysis. Am J Kidney Dis. 2015;66(1):125-32.

31. Pun PH, Middleton JP. Dialysate potassium, dialysate magnesium, and hemodialysis risk. J Am Soc Nephrol. 2017;28(12):3441-51.

\section{Publisher's Note}

Springer Nature remains neutral with regard to jurisdictional claims in published maps and institutional affiliations.

Ready to submit your research? Choose BMC and benefit from

- fast, convenient online submission

- thorough peer review by experienced researchers in your field

- rapid publication on acceptance

- support for research data, including large and complex data types

- gold Open Access which fosters wider collaboration and increased citations

- maximum visibility for your research: over $100 \mathrm{M}$ website views per year

At BMC, research is always in progress.

Learn more biomedcentral.com/submissions 